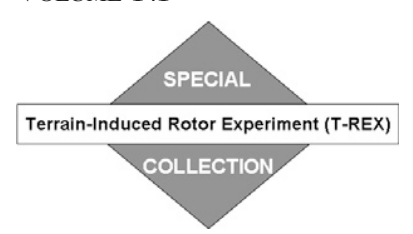

\title{
High-Resolution Doppler Lidar Observations of Transient Downslope Flows and Rotors
}

\author{
CHRISTIAN KÜHNLEIN \\ European Centre for Medium-Range Weather Forecasts, Reading, United Kingdom \\ ANDREAS DÖRNBRACK \\ Institut für Physik der Atmosphäre, Deutsches Zentrum für Luft- und Raumfahrt, Oberpfaffenhofen, Germany \\ MARTIN WeISSMANN \\ Hans-Ertel-Centre for Weather Research, Data Assimilation Branch, Ludwig-Maximilians-Universität, \\ Munich, Germany
}

(Manuscript received 29 August 2012, in final form 4 April 2013)

\begin{abstract}
The authors present observations of the temporal evolution of downslope windstorms with rotors and internal hydraulic jumps of unprecedented detail and spatiotemporal coverage. The observations were carried out by means of a coherent Doppler lidar in the lee of the southern Sierra Nevada range during the sixth intensive observational period of the Terrain-induced Rotor Experiment (T-REX) in 2006. Two representative flow regimes are analyzed and juxtaposed in this paper. The first case shows pulses of high-momentum air that propagate eastward through the valley with an internal hydraulic jump on the leading edge. The region downstream of the transient internal hydraulic jump is characterized by turbulence but no coherent rotor circulation was observed. During the second case, the strongest windstorm of the field campaign T-REX occurred. The observed features of this event resemble the classical notion of a rotor. Altogether, the Doppler lidar observations of both downslope flow events reveal a complex, turbulent flow that is highly transient, intermittent, 3D, and interacts with a significant along-valley flow.
\end{abstract}

\section{Introduction}

In the literature, atmospheric rotors (hereafter denoted as "rotors") are often defined as low-level vortices with horizontal axes parallel to the ridgeline in the lee of mountains (Kuettner 1938, 1939; Glickman and Zenk 2000; Doyle and Durran 2002). Sheridan and Vosper (2006) showed that the occurrence of rotors can be predicted by a flow regime diagram whereby the flow type largely depends on the ratio of mountain height to inversion height and the upstream Froude number. Several studies emphasize that rotor formation involves the dynamical interaction between mountain lee waves and the surface boundary layer (Doyle and Durran 2002;

Corresponding author address: Christian Kühnlein, European Centre for Medium-Range Weather Forecasts, Shinfield Park, Reading RG2 9AX, United Kingdom.

E-mail: christian.kuehnlein@ecmwf.int
Vosper 2004; Hertenstein and Kuettner 2005; Mobbs et al. 2005; Jiang et al. 2007). The adverse pressure gradient induced by the lee waves aloft leads to separation of the downslope flow from the surface. This flow separation is a prerequisite for rotor formation.

The associated turbulence and the large vertical accelerations in rotors pose severe hazards for low-flying aircraft in the vicinity of mountains (e.g., Doyle and Durran 2002; Hertenstein and Kuettner 2005; Darby and Poulos 2006; Dörnbrack et al. 2006). Furthermore, the strong surface wind gusts associated with the downslope flow are responsible for damages near the surface. (Strong winds associated with rotors were made responsible for a train blown off the railroad in Switzerland; see http://www.sturmarchiv.ch/index.php/20070119_02_ Rotorwind_Wasserauen or search for "Rotorwind Wasserauen".)

The earliest scientific glider observations of rotors go back to Kuettner $(1938,1939)$. The Sierra Wave Project 
in the 1950s (Holmboe and Klieforth 1957; Grubišić and Kuettner 2003) was the first coordinated field campaign to "explore the monsters" (Whelan 2000). These observations were mainly guided by individual interests in the strongest and most noteworthy events. Gliders, balloons, and a sparse surface network constituted the experimental platform of this endeavor. However, continuous and area-wide observations of the downslope windstorms and the rotor flow structure in the boundary layer were not possible at that time.

After the Sierra Wave Project, the rotor flow was visualized as a large, quasi-steady, coherent roll with a distinct reversed (or recirculating) flow at low levels toward the mountain range (Ludlam and Scorer 1957). The characterization was complemented by noting that the flow inside the rotor implicates regions of strong and possibly severe turbulence. However, as already pictured by Förchgott (1949) and impressively shown by Hertenstein and Kuettner (2005) using numerical simulations, a variation of the upstream shear at mountaintop level results in a totally different downslope flow and rotor types.

Moreover, observations of downslope flows and rotors revealing the spatial structure in the boundary layer and the temporal evolution were missing. Some ground-based coherent Doppler lidar observations were made in the lee of the Rocky Mountains (Neiman et al. 1988; Ralph et al. 1997; Darby and Poulos 2006), but these studies only included 2D scans parallel to the downslope flow. Therefore, ambiguity remained whether the observed weak reverse flow component was actually a $2 \mathrm{D}$ recirculation or the result of a more complex 3D flow structure. In addition, these studies were based on a limited number of scans to analyze the temporal evolution. Other studies rely on relatively sparse surface measurements (Mobbs et al. 2005; Grubišić and Billings 2007) or in situ measurements on board various research aircraft (Holmboe and Klieforth 1957).

Thus, one of the primary objectives of the Terraininduced Rotor Experiment (T-REX) in 2006 was to observe the full 3D structure of downslope flows and rotors and their temporal evolution by a unique observational network including ground-based sensors and remote sensing instruments, balloons, and research aircraft (Grubišić et al. 2008). Especially, the nearly continuous deployment of two Doppler lidars for about six weeks and one aerosol lidar for about two months (De Wekker and Mayor 2009; Drechsel et al. 2009; Hill et al. 2010) intended to provide spatially and temporally high-resolved observations of the flow structure in the Owens Valley in Southern California.
Preceding studies using the T-REX dataset confirmed that rotors actually consist of smaller entities that are referred to as subrotors by Doyle and Durran (2007). These subrotors represent small-scale vortices of $\mathcal{O}(10$ $100 \mathrm{~m}$ ) in size and are generated by shear instability particularly at the upstream edge of the "parent" rotor. The scale and the high intensity of the subrotors actually pose the largest aeronautical hazard (Doyle et al. 2009; Weissmann et al. 2009). Using high-resolution wind profiler observations, among others, Cohn et al. (2011) found detailed low-level features of downslope flows that were mostly in qualitative agreement with largeeddy simulations by Doyle et al. (2009): a vortex sheet that detaches from the surface and separates the laminar wave flow aloft from the turbulent zone below, subrotors that evolve from the lifted vortex sheet and cause intermittently observed reversed flow, and persistent reversed flow in a shallow layer from the ground to $200 \mathrm{~m}$ above in the region below the lee wave crest.

The purpose of this paper is to present high-resolution observations of the spatiotemporal flow structure during downslope windstorms and under conditions favorable for rotor formation. We juxtapose two selected flow regimes during the sixth intensive observational period (IOP6 on 25-26 March 2006) of T-REX. The flow structure is analyzed by Doppler lidar scans at different elevation and azimuthal angles, as well as time series and temporal averages comprising a multitude of lidar scans for the two cases. The observations were made using a scanning, pulsed, coherent 2- $\mu \mathrm{m}$ Doppler lidar from Lockheed Martin Coherent Technologies. Observations from the same instrument at this location have also been presented in Doyle et al. (2009), Drechsel et al. (2009), Weissmann et al. (2009), and Hill et al. (2010). The lidar observations in the Owens Valley are complemented by wind observations from individual stations of the Desert Research Institute (DRI) surface network, and vertical profiles of dropsondes released from the BAe146-301 research aircraft.

The lidar was situated in the Owens Valley at $36.79^{\circ} \mathrm{N}$, $118.21^{\circ} \mathrm{W}$, and $1240 \mathrm{~m} \mathrm{MSL}$, which is approximately $2 \mathrm{~km}$ west of the town of Independence, California, on the alluvial slopes of the southern Sierra Nevada. The Owens Valley can be characterized as a quasi-twodimensional, south-southeast to north-northwest aligned valley confined by high mountain ridges on either side. The mountain top levels of the Sierra Nevada in the west reach up to $4 \mathrm{~km}$ MSL $(\sim 3 \mathrm{~km}$ above the valley floor), the White-Inyo mountain range in the east reach up to $3 \mathrm{~km}$ MSL, the crest-tocrest distance is $\sim 30 \mathrm{~km}$, whereas the width of the valley is $\sim 15 \mathrm{~km}$. 


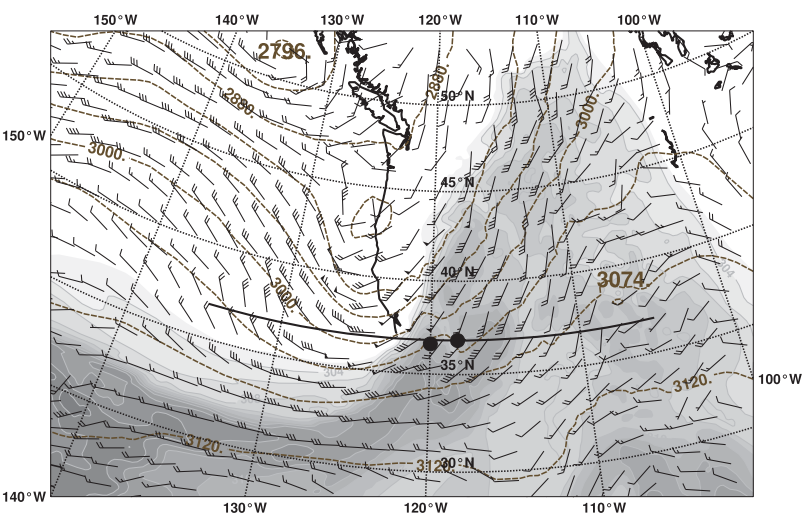

(a)

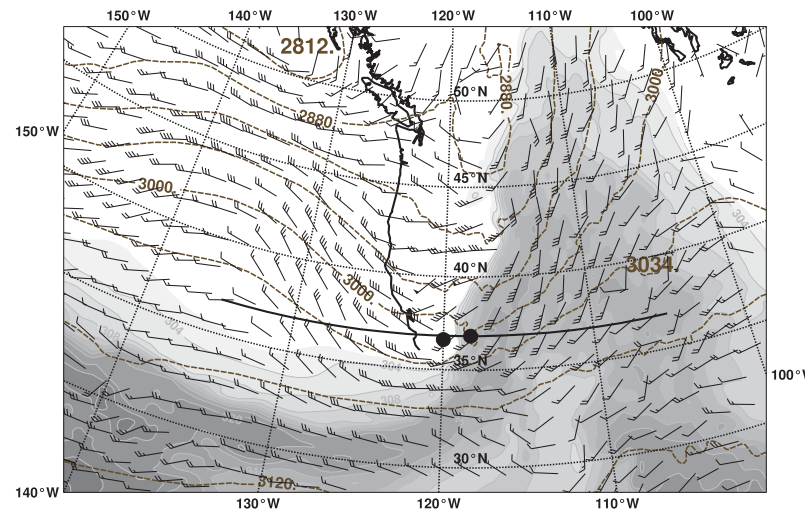

(c)

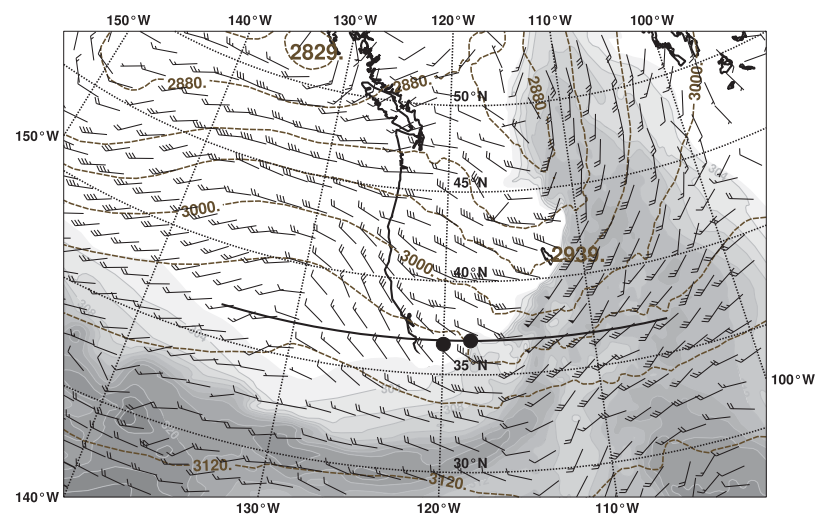

(e)

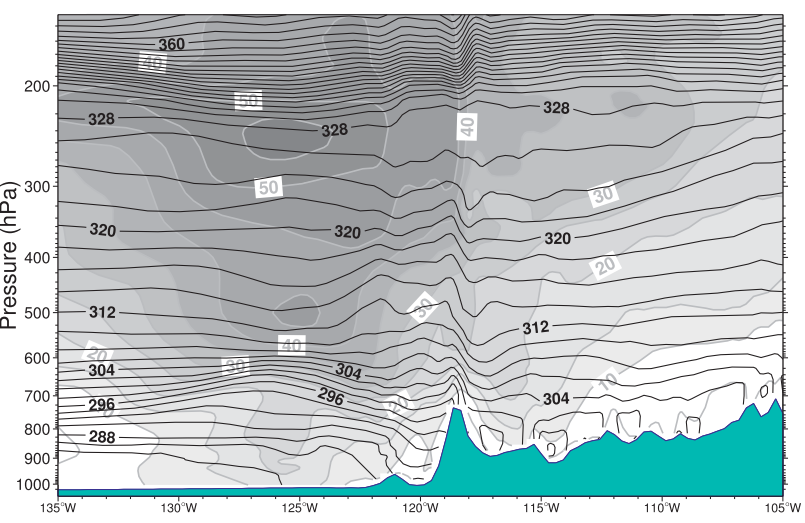

(b)

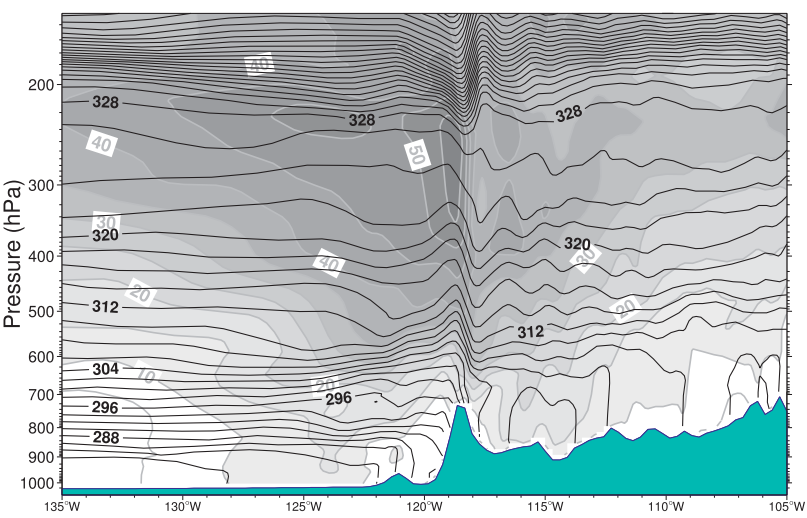

(d)

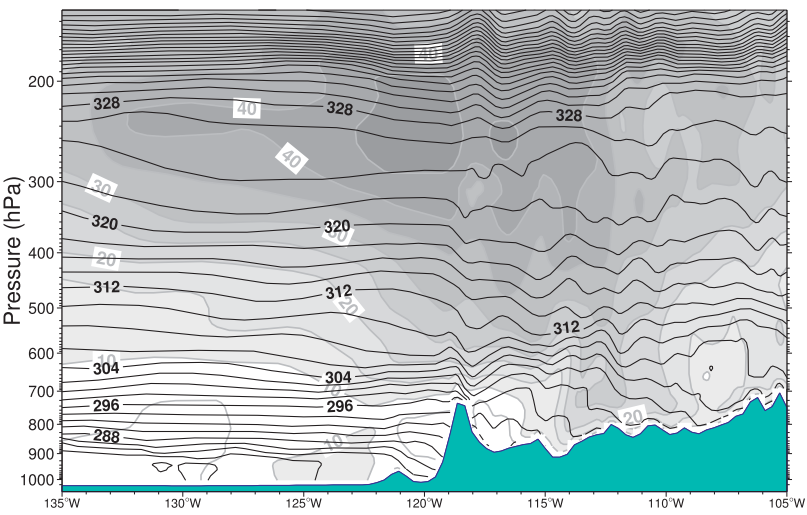

(f)

FIG. 1. ECMWF T799/L91 analyses for (a),(b) 1800 UTC 25 Mar 2006, (c),(d) 0000 UTC 26 Mar 2006, and (e),(f) 0600 UTC 26 Mar 2006. (left) Geopotential height (dashed brownish lines, $\mathrm{m}$ ), horizontal wind speed (barbs, $\mathrm{m} \mathrm{s}^{-1}$ ), and equivalent potential temperature $\theta_{e}>310 \mathrm{~K}$ (gray shading, K) at $700 \mathrm{hPa}$. The two black dots mark Independence, CA (eastern dot), and the position of upstream profiles (Fig. 2) in the Central Valley, CA. (right) Vertical west-east sections along $36.8^{\circ} \mathrm{N}$ showing potential temperature $\theta$ (black lines, K) and horizontal wind magnitude (gray shading, $\mathrm{m} \mathrm{s}^{-1}$ ).

The next section briefly describes the overall meteorological evolution during IOP6. The Doppler lidar observations are presented in section 3. Conclusions will be provided in section 4 .

\section{Synoptic weather situation and upstream profiles}

The temporal evolution of the meteorological situation during IOP6 is depicted in Fig. 1 by means of 
6-hourly European Centre for Medium-Range Weather Forecasts (ECMWF) analyses of geopotential height, wind, and equivalent potential temperature on the 700-hPa pressure surface, as well as of potential temperature and wind in a zonally oriented vertical cross section.

On 25 March 2006, a trough passed the west coast of North America and at 1800 UTC (1000 local time, which is Pacific standard time) the trough axis was located west of the Sierra Nevada. At the leading edge of the trough, and still in the warm sector before the approaching cold front, south-westerly winds strengthened to $\approx 10-15 \mathrm{~m} \mathrm{~s}^{-1}$ and dominated the flow past the Sierra Nevada at the 700-hPa pressure surface. In accordance with Sheridan and Vosper (2012), see their Fig. 4a, the front has made landfall at this time.

In response to the strong cross-mountain wind, internal gravity waves were excited. In a series of papers, the moderate- to large-amplitude waves during this IOP6 were observed and investigated by means of airborne observations conducted onboard the University of Wyoming King Air and the National Science Foundation-National Center of Atmospheric Research Gulfstream V (see Smith et al. 2008; Jiang and Doyle 2009; Doyle et al. 2011a). The ECMWF analysis shows an upward propagating hydrostatic internal gravity wave directly above the highest peak along the cross section (Fig. 1b). During the next 6-12 h, the cold front passed over the Owens Valley (Figs. 1c,e) and due to the eastward propagation of the trough, the $700-\mathrm{hPa}$ winds shifted gradually to northwesterlies upstream of Independence. The maximum wave signal in the ECMWF analyses occurred at 0000 UTC (Fig. 1d) in accordance with wind speeds of $\geqq 10 \mathrm{~m} \mathrm{~s}^{-1}$ around the level of the Sierra crest between 1800 and 0000 UTC (cf. Figs. 2a,b). Later at 0600 UTC, the wave amplitude in the ECMWF analyses is much weaker (Fig. 1f), consistently with the ceasing cross mountain flow (cf. Fig. 2c). The synoptic evolution and wave processes during IOP6 of T-REX are discussed based on high-resolution numerical simulations by Sheridan and Vosper (2012).

The vertical distribution of the wind field and the potential temperature $\theta$ for a selected location in the Central Valley, California, upstream of Independence are depicted in Fig. 2 at the same three times as in Fig. 1. The relevant characteristics of the profiles are the large positive shear of the horizontal wind and the elevated inversion around the altitude of the Sierra Nevada crest; regarding the inversion see also the local maximum of the squared Brunt-Väisälä frequency $N^{2}$. At 0000 UTC in Fig. 2b, the magnitude of the wind shear between 3and 5 -km altitude is $\approx 1.0 \times 10^{-2} \mathrm{~s}^{-1}$. This value of the wind shear, the wind magnitude, as well as the altitude and strength of the inversion in the layer between 3 and $5 \mathrm{~km}$ conform very well with the mobile GPS Advanced Upper-Air Sounding System (MGAUS) Väisälä RS-92 radiosonde upstream sounding launched at 2300 UTC (see Fig. 5 of Sheridan and Vosper 2012). At lower levels, the gradual change of the wind direction from southwesterlies to northwesterlies can be seen in the sign shift of the meridional wind component during the 12-h period.

The upstream upper-level features only change marginally during the period. The wind and $\theta$ profiles show a sharp tropopause at $12-\mathrm{km}$ altitude (i.e., a local maximum in $N^{2}$; see Birner et al. 2002), and the jet stream maximum of $\approx 50 \mathrm{~m} \mathrm{~s}^{-1}$ underneath that level. The stratospheric $\theta$ profiles are characterized by wave oscillations with a vertical wavelength of $\approx 5 \mathrm{~km}$ (not shown). This corresponds quantitatively well with an estimate of the hydrostatic wavelength between 4.4 and $6.2 \mathrm{~km}$ from the Scorer parameter $\ell^{2}$ (see the caption of Fig. 2 for the definition) in the range of $1.0-2.0 \mathrm{~km}^{-2}$ as plotted in Fig. 2. In the lower troposphere, the Scorer parameter decreases with height. This indicates that the upstream profiles are conducive to the formation of trapped lee waves.

\section{Doppler lidar observations}

In this section, we juxtapose Doppler lidar observations of two flow regimes during IOP6: one in the local morning hours before the passage of the cold front and one at local nighttime when the front interacts with the mountain topography. Individual representative lidar snapshots (selected from several thousand scans on this day) are presented, and the temporal evolution is discussed based on lidar Hovmöller diagrams, complemented by surface station measurements.

\section{a. Downslope windstorm with transient internal hydraulic jump}

Figure 3 presents a snapshot of the flow structure in the Owens Valley around 1800 UTC. The rangecorrected aerosol backscatter intensity (Fig. 3a) shows relatively low values $4-9 \mathrm{~km}$ west of the lidar that presumably indicate clean subsiding air. Higher values in the lowest $3 \mathrm{~km}$ above the lidar site and to the east indicate a turbulent boundary layer with increased aerosol content that is likely mineral dust picked up from the valley floor. The boundary layer is capped by a cloud where the base is indicated by the maximum in backscatter intensity at $\approx 4 \mathrm{~km}$ MSL. The elevated croissantshaped region westward of the lidar between 4 - and $7-\mathrm{km}$ altitude indicates remnants of the cap cloud downstream of the Sierra Nevada. 


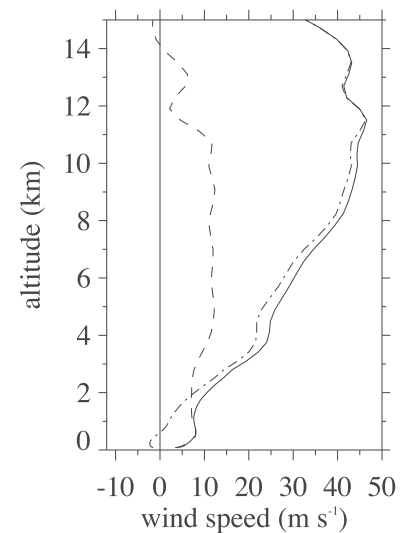

$\begin{array}{lllll}-0.01 & 0.00 & 0.01 & 0.02 & 0.03\end{array}$
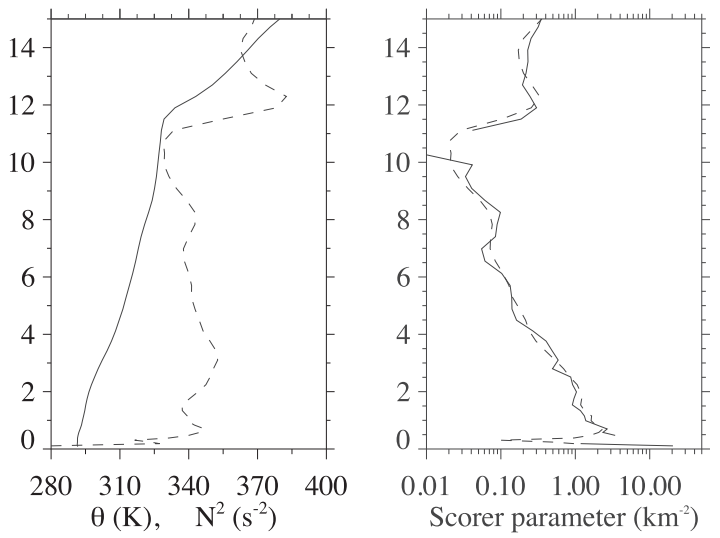

(a)
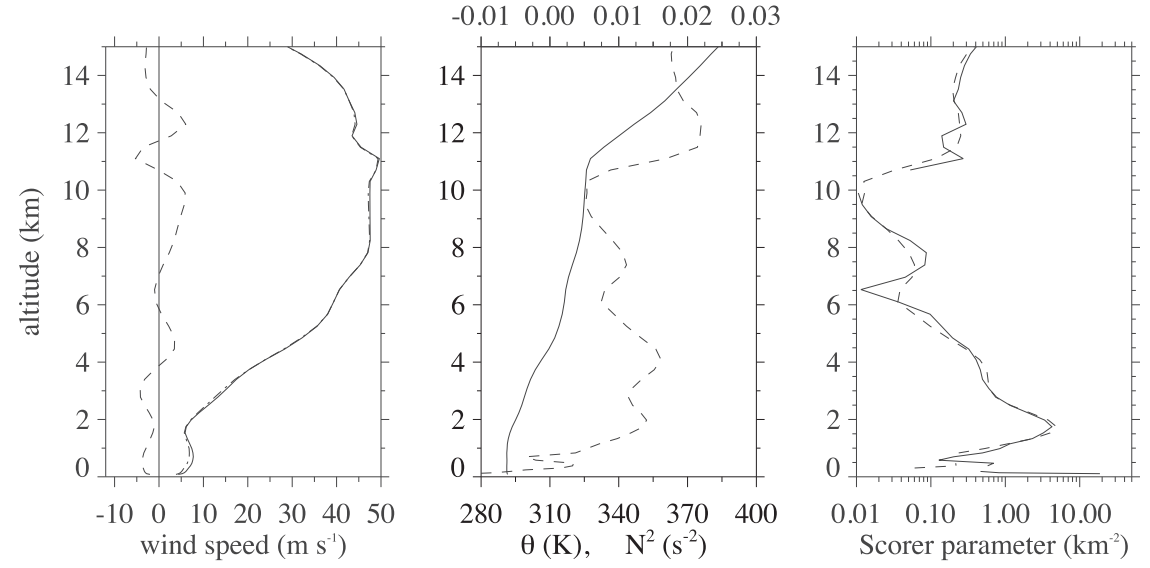

(b)
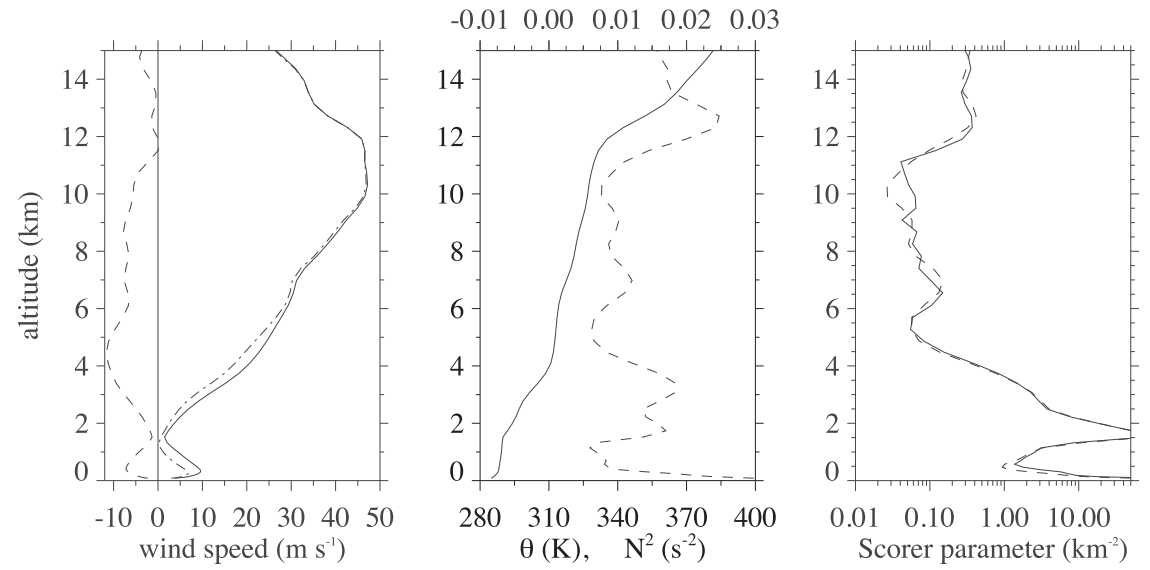

(c)

FIG. 2. ECMWF analysis upstream profiles at $36.6^{\circ} \mathrm{N}, 120^{\circ} \mathrm{W}$ (cf. Fig. 1) valid at (a) 1800 UTC 25 Mar 2006, (b) 0000 UTC 26 Mar 2006, and (c) 0600 UTC 26 Mar 2006. (left) Meridional (dashed line), zonal (dashed-dotted line), and horizontal velocity $v_{h}$ (solid line). (middle) Potential temperature $\theta$ (solid line) and squared Brunt-Väisälä frequency $N^{2}=g / \theta \partial \theta / \partial z$ (dashed line). (right) Scorer parameter $\ell^{2}=N^{2} / v_{h}^{2}-\left(1 / v_{h}\right) \partial^{2} v_{h} / \partial z^{2}$ without (dashed line) and with curvature term (solid line). 


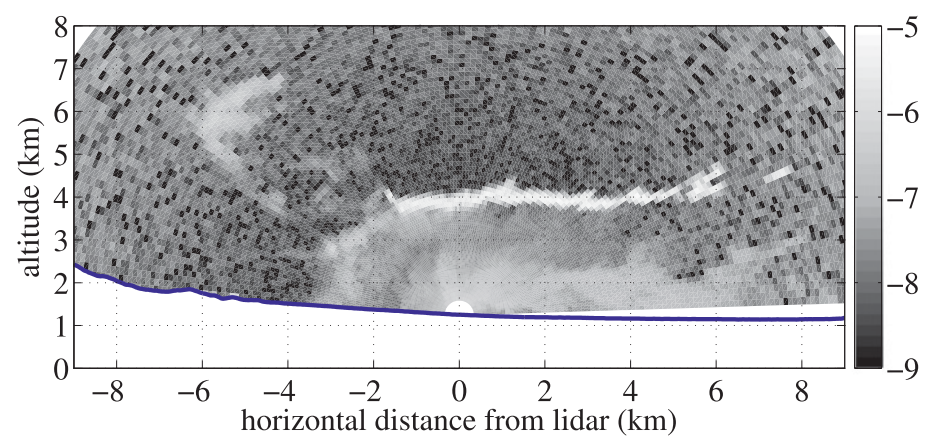

(a)

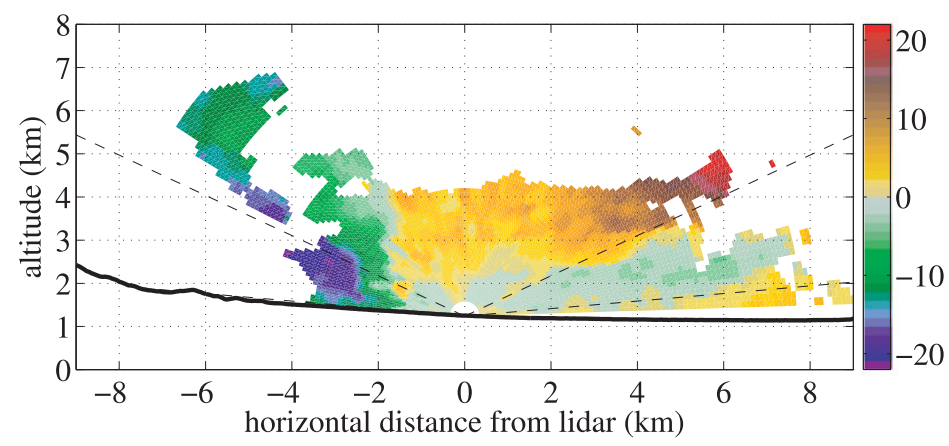

(b)

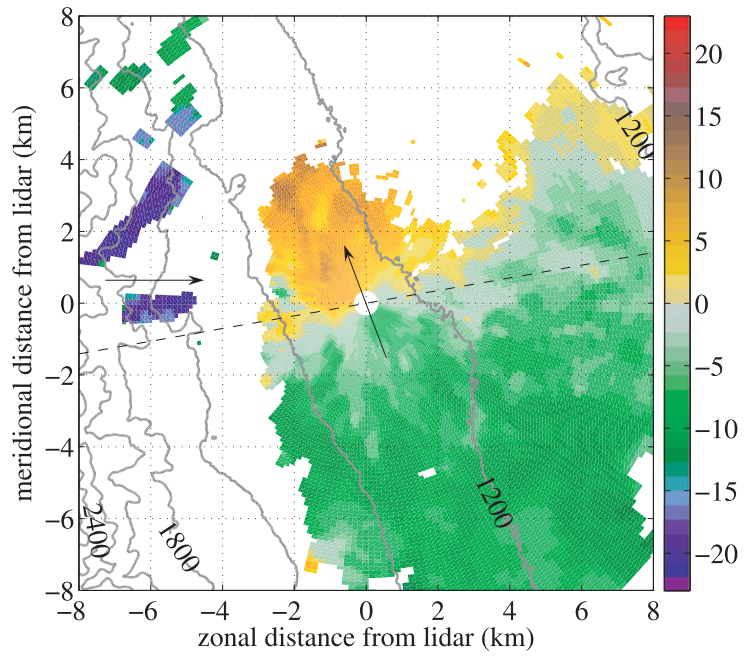

(c)

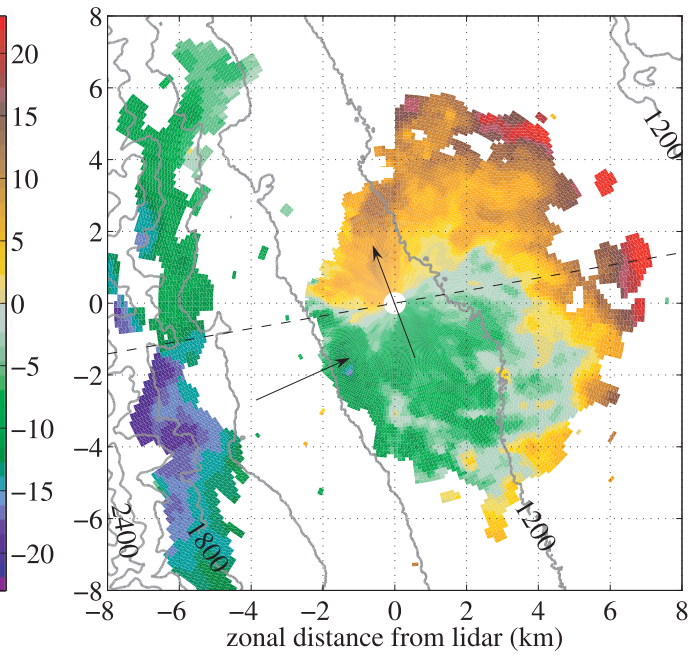

(d)

FIG. 3. Vertical-slice lidar scans of (a) range-corrected aerosol backscatter intensity and (b) radial velocity $\left(\mathrm{m} \mathrm{s}^{-1}\right.$, shaded) at 1807:37 UTC 25 Mar 2006. The blue and black thick lines in (a) and (b) represent the surface. The dashed lines in (b) show the elevation angles of the (c),(d) conical scans. The azimuthal angle of the vertical-slice scans is $80^{\circ}$ from north, as indicated by the dashed black line in (c) and (d). Conical lidar scans with elevation (c) $5^{\circ}$ and (d) $25^{\circ}$ of radial velocity $\left(\mathrm{m} \mathrm{s}^{-1}\right.$, shaded) at 1758:51 and 1800:45 UTC, respectively. Surface altitude ( $\mathrm{m}$, gray contour lines, $\Delta=$ $200 \mathrm{~m}$ ). Arrows point out the main wind direction. A lidar scan of $180^{\circ}$ took $30 \mathrm{~s}$.

The lidar scans of radial velocity (negative values denote the flow toward, positive values away from the lidar) show strong westerly downslope winds of up to $\approx 20 \mathrm{~m} \mathrm{~s}^{-1}$ to the west of the lidar. The conical scan at the elevation angle of $5^{\circ}$ (Fig. 3c) reveals moderate southeasterly winds $<8 \mathrm{~m} \mathrm{~s}^{-1}$ in the lower part of the boundary layer near the lidar site and to the east. The larger range of the lidar observations toward the southeast indicates 

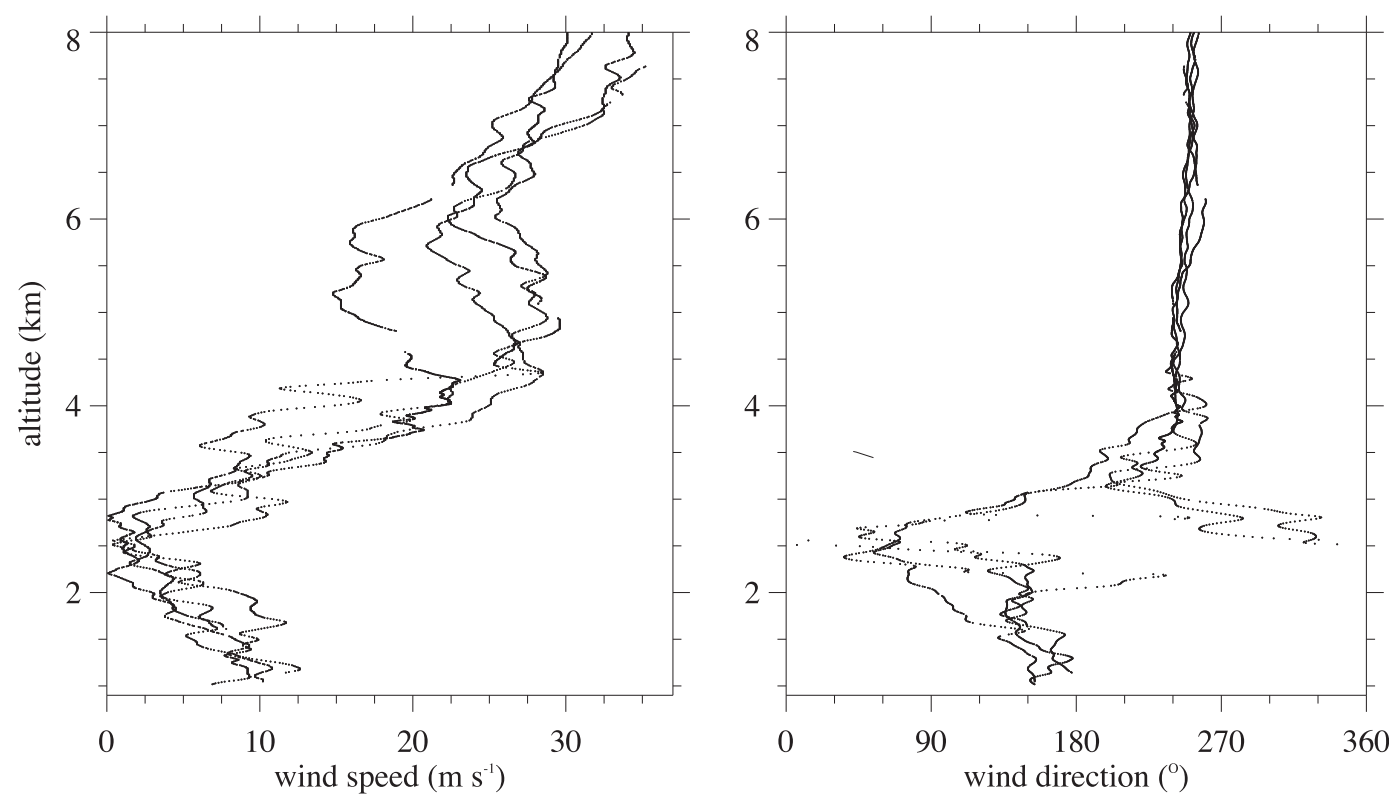

FIG. 4. Vertical profiles of (left) wind speed and (right) wind direction of four dropsondes deployed from the BAe146-301 research aircraft above the Owens Valley. The four dropsondes were released in 30-s intervals from $\sim 1741$ UTC 25 Mar 2006, and the dropsondes required $\sim 10 \mathrm{~min}$ to descend from the flight altitude of $\sim 8.5 \mathrm{~km}$ to the valley floor. The release positions are centered around $36.66^{\circ} \mathrm{N}, 118.19^{\circ} \mathrm{W}$. The dropsondes touched ground level around $36.70^{\circ} \mathrm{N}, 118.10^{\circ} \mathrm{W}$, which is $\sim 14 \mathrm{~km}$ south-southeast of the lidar within the Owens Valley.

abundant aerosols that are transported in the southeasterly flow from one of the main aerosol sources in the valley, the dry Owens Lake, and other adjacent desertified areas (Jiang et al. 2011).

In contrast to the southeasterly flow in the first range gates of the $25^{\circ}$ elevation angle scan, westerly flow prevails at higher altitudes (Fig. 3d). This is in agreement with the apparent west wind near the cloud base in the vertical-slice scan (Fig. 3b). The arrow at about $(x=-2$, $y=-2 \mathrm{~km}$ ) in Fig. 3d marks the downslope wind from the mountains that penetrated into the southeasterly boundary layer winds. The gap between the high-speed winds $\left(v_{\text {rad }} \approx-18 \mathrm{~m} \mathrm{~s}^{-1}\right)$ farther aloft and the region around the lidar indicates scarcity of backscattering aerosols in descending high-altitude air along the alluvial slopes of the Sierra Nevada.

The elevated narrow band of weak easterly flow in the vertical-slice scan (Fig. 3b) at first glance suggests a flow reversal associated with a rotor. However, the subsequent analysis does not reveal a coherent rotor circulation for the present flow regime, and suggests the prevailing flow along the valley as a main cause of the easterly flow component in the vertical-slice scans.

For instance, the conical scans in Figs. $3 \mathrm{c}$ and $3 \mathrm{~d}$ show the significant southeasterly along-valley flow. This southeasterly along-valley flow in the conical scans deviates by $\approx 10^{\circ}$ (i.e., consider the orientation of the line of zero radial velocity $v_{\text {rad }}$ ) from the vertical-slice scan, as indicated by the dashed line. Therefore, the along-valley flow is projected onto the vertical-slice depiction, resulting in an easterly component.

The BAe 146 dropsonde profiles of horizontal wind magnitude and direction presented in Fig. 4 show westerly winds above an altitude of $\approx 3.5 \mathrm{~km}$, which coincides approximately with the mountaintop level of the Sierra Nevada. Within the Owens Valley and at altitudes lower than $\approx 2 \mathrm{~km}$, southeasterly winds are roughly aligned with the valley axis. This is in agreement with the interpretation of our lidar observations at this time (e.g., in Figs. $3 c$ and 5c). In between the two well-defined layers, a transition zone exists where the wind vector rotates from the southeasterlies to the westerlies and where its magnitude becomes small. We interpret this pattern as result of overturning vortices in the corresponding shear layer. The occasional appearance of easterly winds, although very small in magnitude $\left(<2.5 \mathrm{~m} \mathrm{~s}^{-1}\right)$, could be related to elevated vortices in the roll clouds. The described features of the BAe 146 dropsonde profiles are also seen in the radiosonde profiles launched from the ISS-MAPR site ${ }^{1}$ at 1700 and 2000 UTC (not shown).

\footnotetext{
${ }^{1}$ The Integrated Sounding System (ISS)-Multiple Antenna Profiler (MAPR) site was located at the center site in OwensValley, about $1.5 \mathrm{~km}$ southeast of the town of Independence, California.
} 


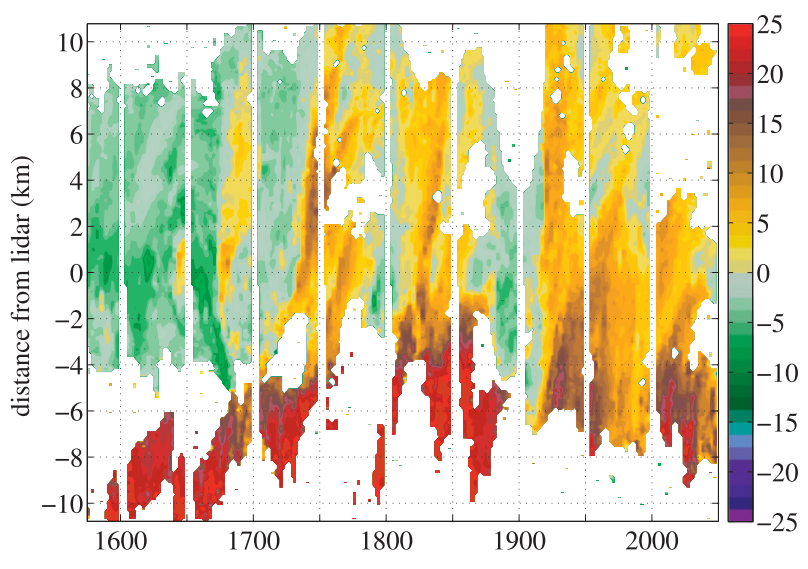

(a)

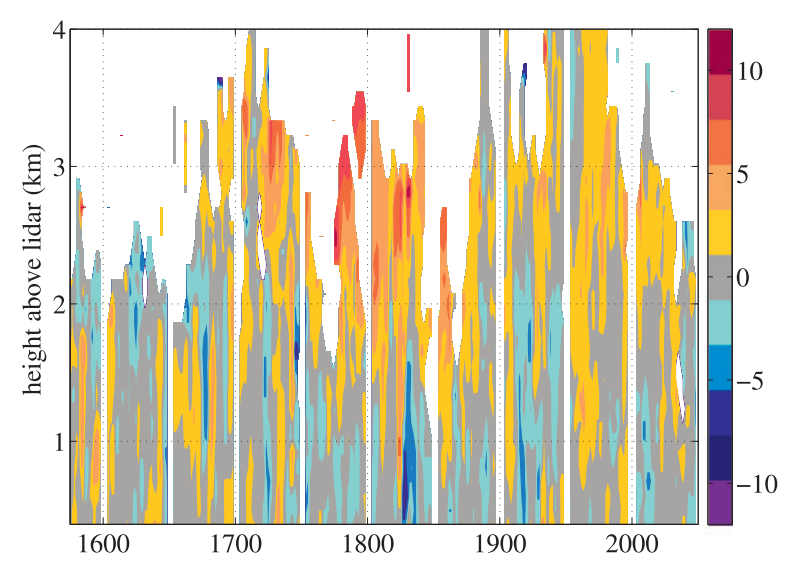

(b)

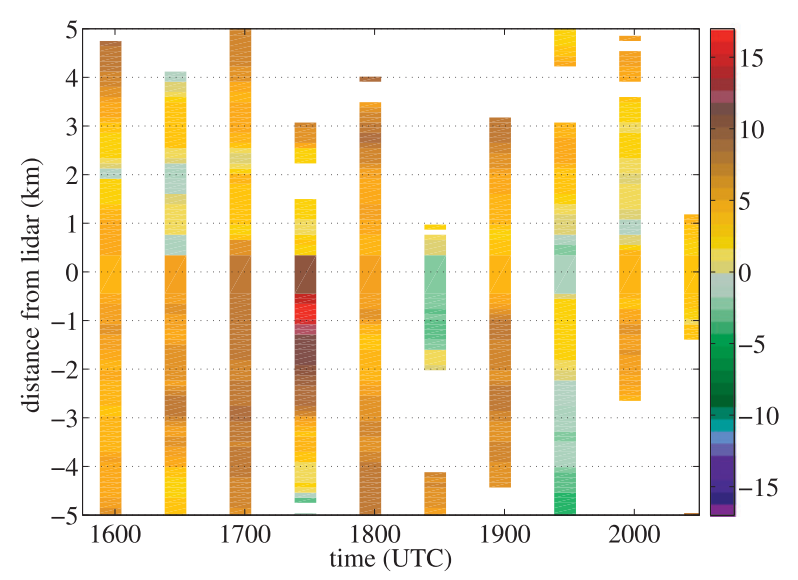

(c)

FIG. 5. Hovmöller diagrams in the period 1545-2030 UTC 25 Mar 2006. (a) Cross-valley near-surface velocity along the dashed line in Fig. $3 \mathrm{c}$ (negative radial velocity at elevation $=165^{\circ}$ upstream of lidar and radial velocity elevation $=0^{\circ}$ downstream of lidar); (b) vertical velocity above lidar; (c) along-valley near-surface velocity perpendicular to cross section in (a) (negative radial velocity at elevation $=5^{\circ}$ south of lidar and radial velocity elevation $=175^{\circ}$ north of lidar). Positive velocity indicates westerly, upward and southerly wind components in (a)-(c); units are in $\mathrm{ms}^{-1}$.
At a distance of $\approx 2 \mathrm{~km}$ west of the lidar, the radial velocity $v_{\text {rad }}$ rapidly changes from negative to positive values (Fig. 3b). At the same position, the backscatter intensity increases due to an enhanced aerosol concentration (Fig. 3a). As the source of the aerosol particles is most probably the surface, this zone of strong horizontal convergence indicates a rapid vertical ascent. We denote this region as an internal hydraulic jump in which the fast deceleration of the downslope wind enforces an upward motion (Armi and Mayr 2011).

However, there is no indication of a downward motion below the cloud base east of the internal hydraulic jump. A significant descent would be associated with a divergence in $v_{\text {rad }}$ somewhere below the cloud base, which is not present. Furthermore, regions of strong descent would likely lead to an evaporation of the cloud particles at the top of the boundary layer and a decrease of the backscatter intensity. The nearly horizontal and coherent structure of the high backscatter values at the cloud base does not support such a process (Fig. 3a). In addition to the lidar observations, roll clouds with a base at around 4-km altitude along the Owens Valley were observed during this time [cf. Fig. 6 in Jiang et al. (2011) and Figs. 6a,b in Sheridan and Vosper (2012)].

Another feature of our observations was the violent temporal and spatial variation of the observed flow in the valley. Figure 5 depicts Hovmöller diagrams of $v_{\text {rad }}$ (with reversed sign west and south of the lidar) for different lidar beam orientations. The Hovmöller diagram along the $80^{\circ}$ azimuth from low elevation scans (Fig. 5a) shows the near-surface zonal flow: weak winds with a component toward the Sierra Nevada dominated the flow in the valley during the early morning hours until about 1700 UTC. We suppose that this very shallow flow is the low-level flow response to the adverse pressure gradient induced by the amplifying mountain lee waves. Vertical lidar scans reveal that this reversed flow is restricted to the lowest $500 \mathrm{~m}$ (not shown). Afterward, the nearly steady flow regime was interrupted by pulses of westerly downslope winds. The consecutive tilted patterns of enhanced $v_{\text {rad }}$ represent downslope wind pulsations with a period of $\approx 60 \mathrm{~min}$. These outbreaks were imbedded in periods of weak winds. The strongest downslope winds occurred near the mountains with values of $\left|v_{\text {rad }}\right|>25 \mathrm{~m} \mathrm{~s}^{-1}$. Near the lidar and in the valley, values of $\left|v_{\text {rad }}\right|>15 \mathrm{~m} \mathrm{~s}^{-1}$ were observed.

As mentioned above, a rough estimate for a convergence zone as proxy for the location of the internal hydraulic jump is the position where positive $v_{\text {rad }}$ values switch to negative ones. This location propagated eastward with downbursts of high-momentum air into the valley whereby $v_{\text {rad }}$ values slowed down east of the lidar site. Large eastward propagation speeds of the internal 

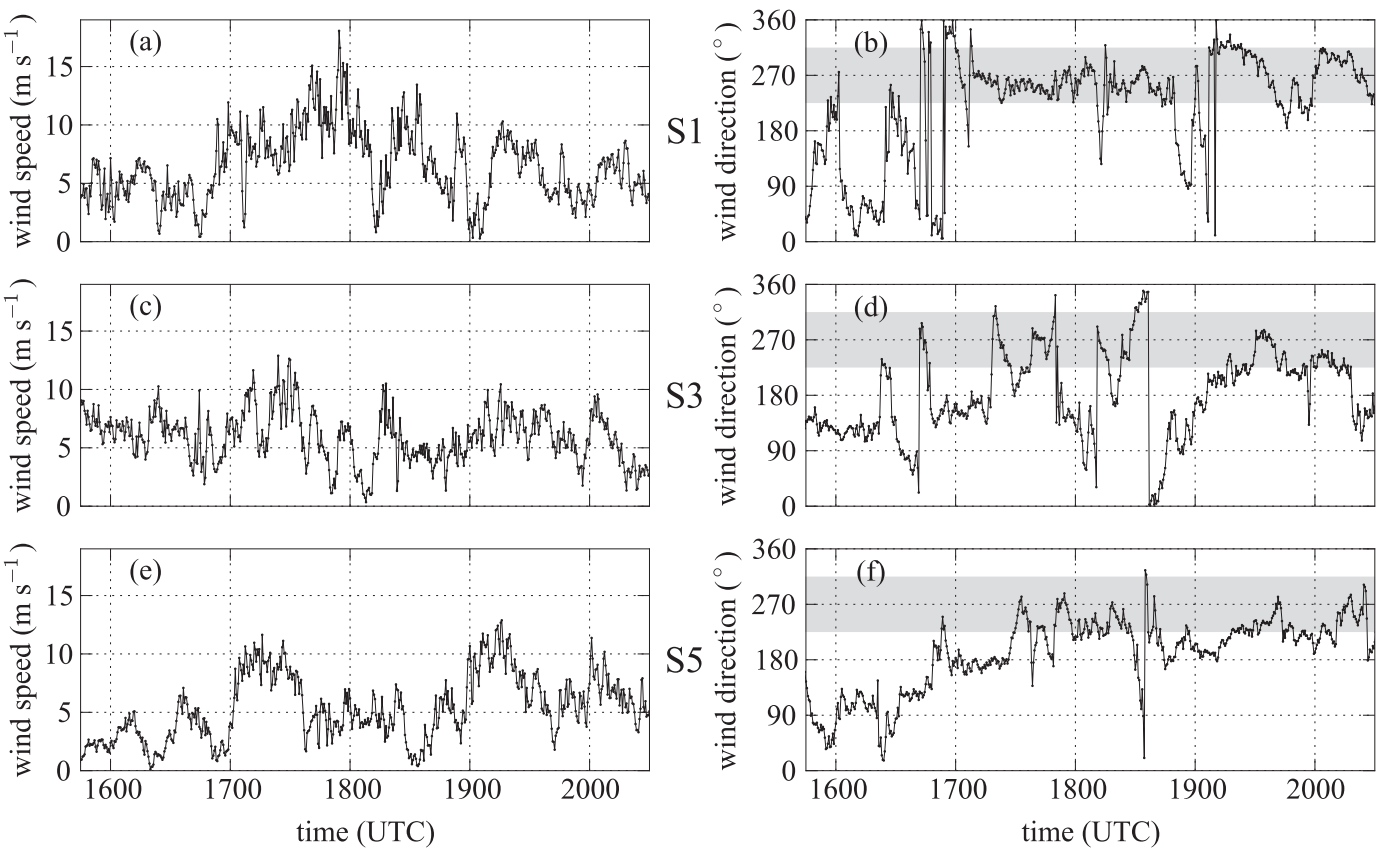

FIG. 6. Surface station measurements of (a),(c),(e) wind speed and (b),(d),(f) wind direction in the period from 1545 to 2030 UTC 25 Mar 2006. The gray shading in (b),(d),(f) highlights westerly winds in the range $270^{\circ} \pm 45^{\circ}$. Three different surface stations are shown in (a),(b); (c),(d); and (e),(f), which correspond to stations 1, 3, and 5 of the DRI surface network of T-REX. The shown surface stations are centered in a west-southwest to east-northeast oriented line around the position of the lidar. The position of station 3 in (c),(d) conforms very closely with the position of the lidar, the westward station 1 in (a),(b) and the eastward station 5 in (e),(f), respectively, are both $\sim 6.5 \mathrm{~km}$ away from the lidar; cf. also Fig. 1 in Doyle et al. (2009).

hydraulic jump can be estimated from Fig. 5a (e.g., $\approx 5 \mathrm{~m} \mathrm{~s}^{-1}$ between 1700 and 1730 UTC). Although the observations in Fig. 5a show a convergence zone where the westerly downslope flow decelerates and the air is forced to rise, there is no indication of a comparable divergence zone associated with a downward motion farther east in the valley (i.e., no downwelling branch of a rotor circulation was observed at low altitudes).

Figure $5 \mathrm{~b}$ presents the vertical velocity above the lidar location. At heights larger than $\approx 2 \mathrm{~km}$, upward motion dominates. We interpret this upward motion as the ascending part of the mountain lee wave above the boundary layer, possibly enhanced by cloud condensational heating. Extrema in the vertical velocity field are potentially related to shear and/or convective instabilities and associated turbulence. Lower levels show frequent changes in the sign of the vertical velocity. At several times comparably large negative values followed positive values close to the ground (e.g., after 1800 UTC and shortly after 1900 UTC). We conjecture that this is the signature of the internal hydraulic jump propagating across the lidar location. This interpretation is assisted by the simultaneous eastward propagation of westerly high-momentum air into the valley (Fig. 5a).
Observations of the wind component along the valley axis were made every $30 \mathrm{~min}$ (Fig. 5c). Until 1800 UTC, the flow near the lidar site is dominated by southerly, upvalley flow. During the period of strong downslope wind gusts, the up-valley flow is interrupted and the alongvalley wind components are around zero near the lidar (e.g., at 1830, 1930, and 2000 UTC).

The lidar observations are supported by surface station measurements in Fig. 6, which are shown here for the same period as the Hovmöller diagrams in Fig. 5. The location of station 3 displayed in Figs. $6 \mathrm{c}$ and $6 \mathrm{~d}$ corresponds very closely to the lidar position. Particularly at this station, the intervals of westerly downslope winds that propagate across the valley alternate with the southeasterly along-valley flow. The timing of the different regimes and the respective wind magnitudes illustrate the same evolution as seen in Figs. 5a and 5c; for example, compare the westerly wind maxima at around 1730 and 1815 UTC. In addition, the surface measurements indicate similarly the various eastward progressions of the downslope winds. For instance, the peak shortly before 1800 UTC in Figs. 6a and $6 \mathrm{~b}$ is followed by the peak at 1815 UTC in Figs. $6 \mathrm{c}$ and $6 \mathrm{~d}$, and an expected weaker signal shortly before 


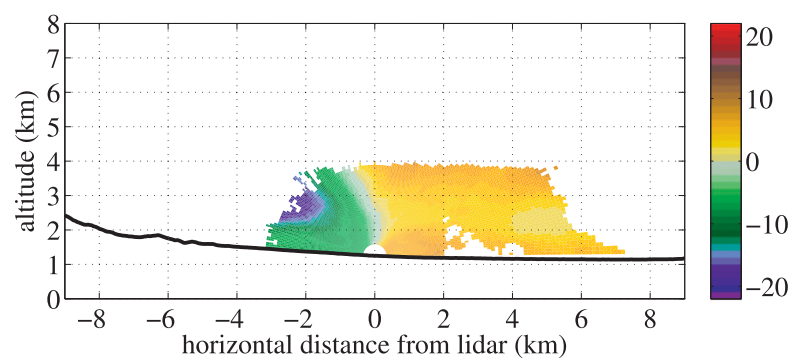

(a)

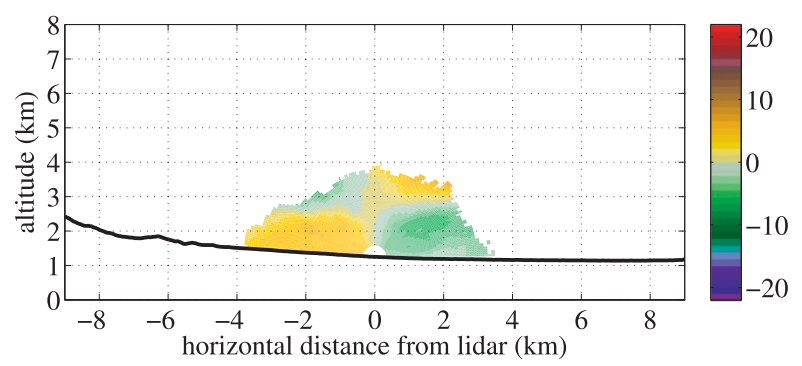

(b)

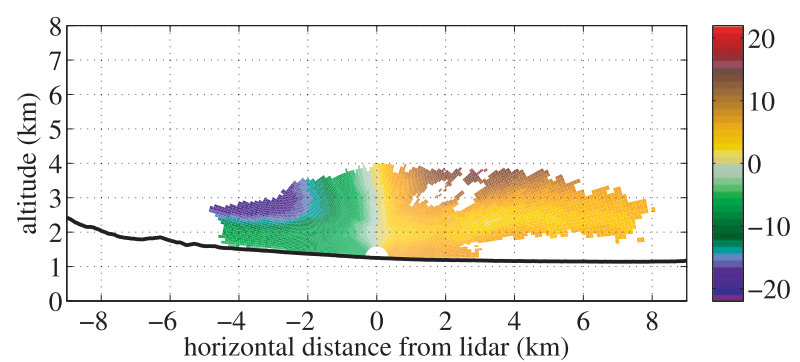

(c)

FIG. 7. Vertical slices of 10-min-averaged radial velocity $\left(\mathrm{m} \mathrm{s}^{-1}\right.$, shaded) from selected periods during the prefrontal observations. The averaging periods are (a) 1812-1822, (b) 1848-1858, and (c) 1912-1922 UTC 25 Mar 2006 (cf. the Hovmöller diagrams in Fig. 5). The black thick line represents the surface. The azimuthal angle of the vertical slices is $80^{\circ}$ from north (cf. Fig. 3).

1830 UTC is seen in Figs. 6e and 6f for station 5, which is farthest away from the Sierra Nevada.

Figure 7 presents vertical slices of the time-averaged radial velocity $v_{\text {rad }}$ over selected 10 -min intervals. Temporal averages of the lidar measurements were possible in these time intervals because of the continuous presence of backscattering aerosols. Two states of the flow are revealed: westerly winds throughout the valley (Figs. $7 \mathrm{a}, \mathrm{c}$ ) and westerly winds above $\approx 2.7-\mathrm{km}$ altitude with easterly winds below (Fig. 7b). The averaging periods correspond to either the westerly or the easterly phases in the Hovmöller diagram of Fig. 5a. As discussed above, the low-level easterly winds in Fig. 7b result as the projection of the southeasterly along-valley wind (see the positive velocities in Fig. 5c at 1900 UTC) onto the vertical-slice scan.

\section{b. Downslope windstorm with transient rotor flow}

Figure 8 shows Doppler lidar observations during the early night hours local time. The vertical-slice lidar scan depicts strong downslope winds exceeding $20 \mathrm{~m} \mathrm{~s}^{-1}$ at the lidar site and upstream (Fig. 8b). Here, the downslope winds penetrate deeper into the valley and show higher values close to the surface compared to the morning event. The high-wind region extends farther east along an inclined line under which regions of reversed flow occur. The backscatter intensity in the boundary layer is enhanced downwind of the lidar, which indicates emission of mineral dust from the valley floor. Similar to Fig. 3, the boundary layer was capped by clouds with a base at $4-5 \mathrm{~km}$ MSL. The inclined line of $v_{\text {rad }}=0$ does not correspond exactly with the sloped pattern of enhanced aerosol backscatter. The gradual increase of aerosol backscatter intensity indicates a turbulent mixing region between clean air of the downstorm winds and the raised dust particles.

The conical scans at $5^{\circ}$ elevation at two times as depicted in Figs. 8c and 8d reveal the horizontal flow structure: several streaks of strong downslope flow point toward the lidar, whereas northerly flow prevails at the valley floor. The fingerlike streaks of downslope flow reach into the northerly along-valley flow and the associated convergence zone denotes the flow separation region of an internal hydraulic jump. Based on the existence of clearly defined divergence zones, for example, around the position $(x=2, y=1 \mathrm{~km})$ in Fig. $8 \mathrm{c}$ and $(x=5, y=2 \mathrm{~km})$ in Fig. $8 \mathrm{~d}$ together with the distinct reversed flow component $2-4 \mathrm{~km}$ east of the lidar, we interpret this flow realization as a rotor interacting with a northerly along-valley flow.

Hovmöller diagrams in Fig. 9 depict the temporal evolution of the flow in the valley around the times of the snapshots in Fig. 8. One of the main features in Fig. 9a is the strong downslope flow with westerly nearsurface winds $>20 \mathrm{~m} \mathrm{~s}^{-1}$ that extends deep into the Owens Valley at early times before around 0230 UTC. At its forefront, a separation region marks the transition to the weaker zonal winds to the east. This is the position of flow convergence associated with an internal hydraulic jump. Subsequently, the separation region propagates westward in accordance with the strong westerly winds retreating toward the Sierra Nevada. The separation region passed the location of the lidar at around 0300 UTC. Up to this time, its average propagation speed was $\approx-4 \mathrm{~m} \mathrm{~s}^{-1}$. The separation region remained almost stationary at this position from around 0300 to 0330 UTC (cf. also Figs. 8c,d at these times), and continued retreating westward thereafter. 


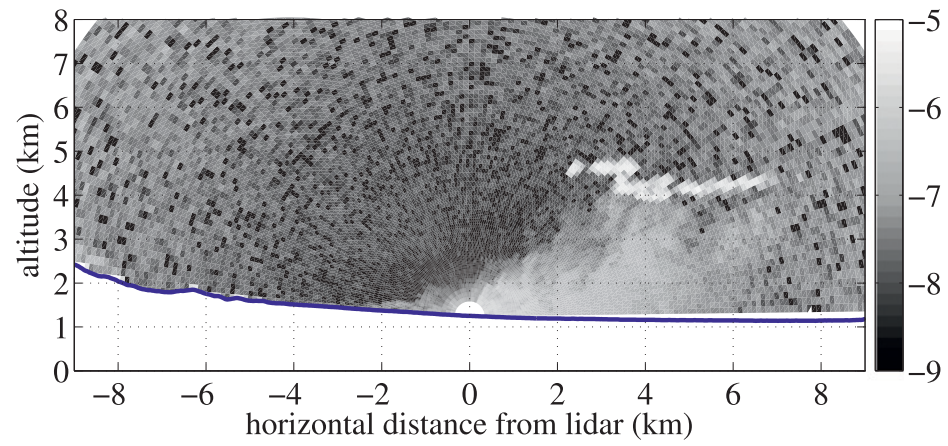

(a)

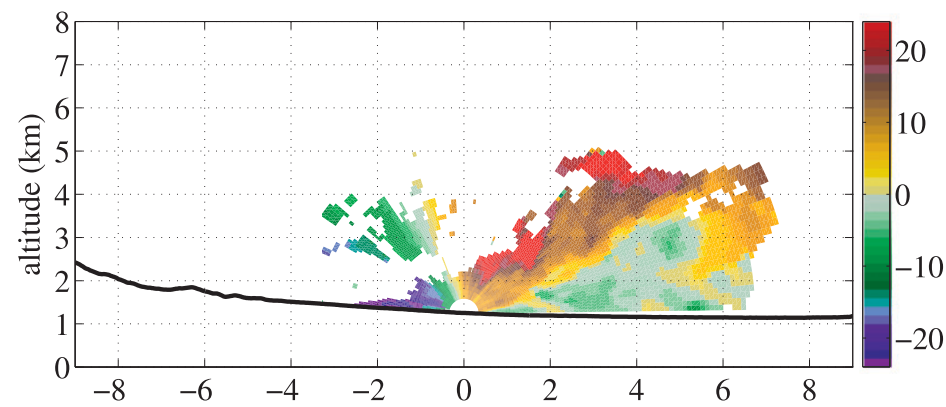

(b)

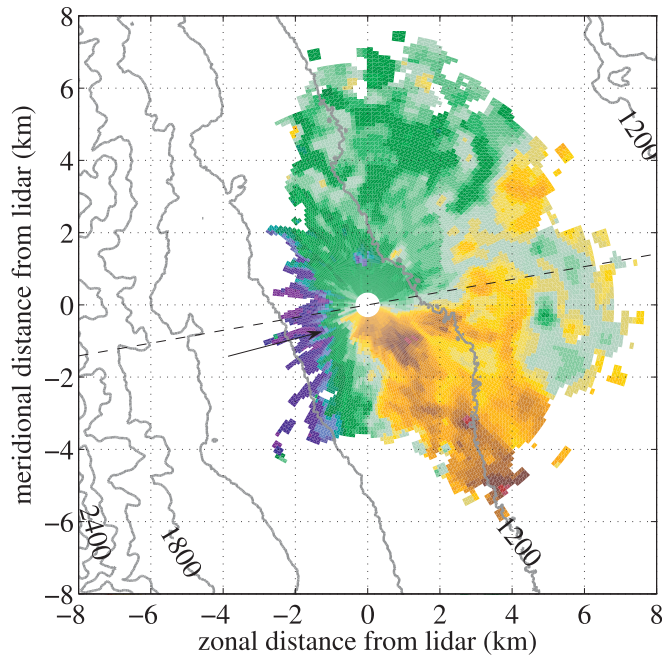

(c)

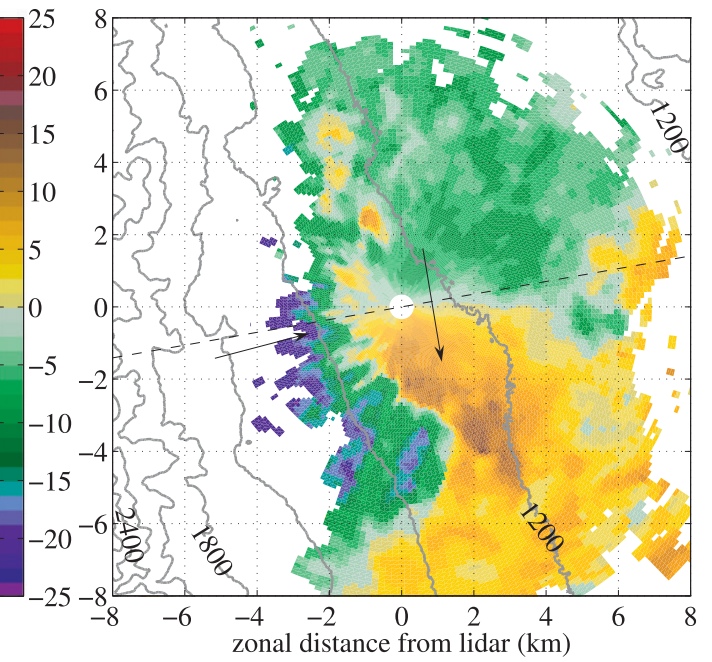

(d)

FIG. 8. Vertical-slice lidar scans of (a) range-corrected aerosol backscatter intensity and (b) radial velocity ( $\mathrm{m} \mathrm{s}^{-1}$, shaded) at 0304:05 UTC 26 Mar 2006. Conical lidar scans with elevation $5^{\circ}$ showing radial velocity ( $\mathrm{m} \mathrm{s}^{-1}$, shaded) at (c) 0259:21 and (d) 0329:19 UTC. See Fig. 3 for further details.

The signature of the separation region can also be discerned from the observed vertical velocity in Fig. $9 \mathrm{~b}$. Before about 0245 UTC, weak downward motion dominated in the strong downslope winds (cf. Fig. 9a). The passage of the separation region over the location of the lidar coincides with the occurrence of substantial upward motion between 0245 and 0345 UTC. Vertical wind speeds of $\approx 10 \mathrm{~m} \mathrm{~s}^{-1}$ were observed from $\approx 500 \mathrm{~m}$ to $>3 \mathrm{~km}$ above the surface. A detected maximum of the vertical wind was $>15 \mathrm{~m} \mathrm{~s}^{-1}$, shortly before $0330 \mathrm{UTC}$ at a height of $\approx 2 \mathrm{~km}$. Downward motion set in below an altitude of $\approx 1 \mathrm{~km}$ after 0330 UTC in the region eastward 


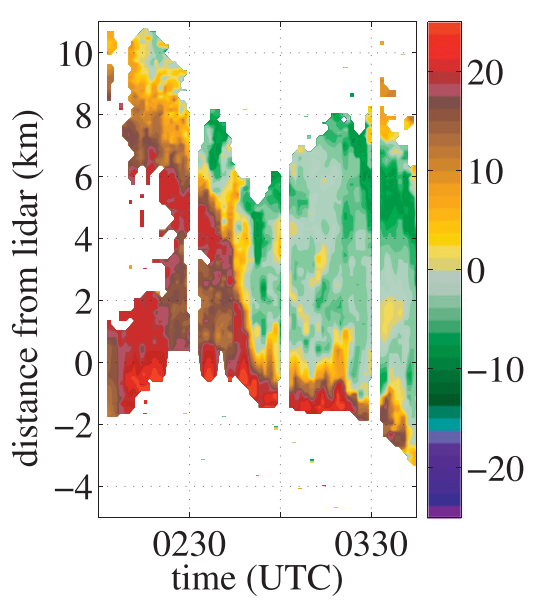

(a)

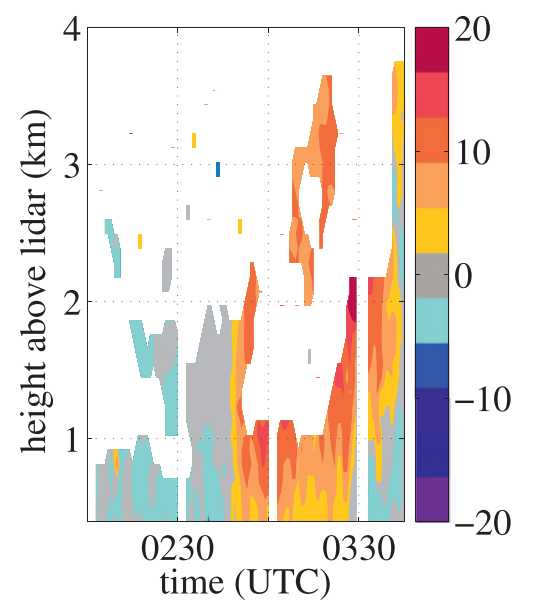

(b)

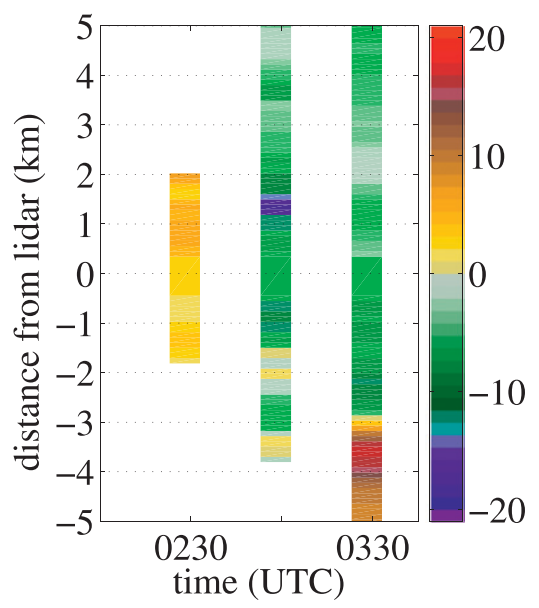

(c)

FIG. 9. Hovmöller diagrams in the period from 0200 to 0345 UTC 26 Mar 2006. (a) Cross-valley velocity, (b) vertical velocity, and (c) along-valley velocity; see Fig. 5 for details.

of the separation region. The relatively long duration of the upward vertical wind regime can be explained by the slow propagation of the separation region in the period between 0245 and 0345 UTC, along with the sloped appearance of the upward motion.

The other main feature of the Hovmöller diagram in Fig. 9a is the existence of distinct regions of reversed near-surface flow with values of $\approx-10 \mathrm{~m} \mathrm{~s}^{-1}$ eastward of the separation region. These localized spots are embedded in the weak northerly along-valley flow. Preferentially, they occur at two different places. First, close to the westward-propagating separation zone indicating flow convergence. Second, they appear farther downstream (cf. the inclined region of reversed flow at a distance of $7 \mathrm{~km}$ eastward from the lidar at around 0330 UTC). There, adjacent positive $v_{\text {rad }}$ values east of the reversed flow indicate a divergence zone, which is interpreted as the signature of the downwelling branch of a rotor. Again, the westward propagation of this observed flow feature with an average propagation speed of $\approx-3 \mathrm{~m} \mathrm{~s}^{-1}$ suggest the existence of a transient rotor flow at these times.

Observations of the near-surface wind along the valley axis (Fig. 9c) show weak negative velocities at 0230 UTC that indicate a light southerly component of the strong downslope flow at that time (cf. Fig. 9a); note that the scans depicted in Fig. $9 \mathrm{c}$ are not exactly parallel to the Sierra Nevada ridge but deviate a few degrees toward the north. The observations at 0230 UTC also suggests that the strong westerly wind intrusion into valley encompassed (at least) an extent of $4 \mathrm{~km}$ along the valley (i.e., $2 \mathrm{~km}$ to the south and to north of the lidar). The observations at 0300 and 0330 UTC show a prevailing northerly flow in the boundary layer eastward of the separation region. Extremely large convergence in the wind field, changing from $\approx 18$ to $\approx-10 \mathrm{~m} \mathrm{~s}^{-1}$ within a distance of about $1 \mathrm{~km}$, is observed to the south of the lidar at 0330 UTC. This demonstrates a substantial along-valley flow variation.

The surface station observations near the lidar site (station 3) are displayed in Figs. 10e and 10f. Station 2, located in the middle of stations 1 and 3 , has also been added in Figs. 10c and 10d compared to Fig. 6 to track the signal of the internal hydraulic jump propagating toward the Sierra. As in the Hovmöller diagrams of Fig. 9 , the winds from the surface stations indicate the westward propagation of the internal hydraulic jump across the valley. The internal hydraulic jump and the associated separation region marks the position when the strong westerly downslope winds switch to the weaker northerly along-valley winds present around this time; see in particular Figs. 10c-f. At the most easterly station 5 in Figs. 10g and 10h, intervals of northeasterly flow are present, likely associated with the intervals of reversed flow observed in Fig. 9a. As expected from the lidar observations, at the station 1 closest to the Sierra Nevada in Figs. 10a and 10b, the westerly downslope winds prevailed throughout the considered period. The magnitudes of the downslope winds in Fig. 10 are substantially higher than during the morning event shown in Fig. 6.

Figure 11 presents time-averaged values of the radial velocity calculated after the transient period of downslope windstorm. In contrast to the pulsating occurrence of the internal hydraulic jump in the morning case of section $3 \mathrm{a}$, a fairly persistent recirculating zone was 

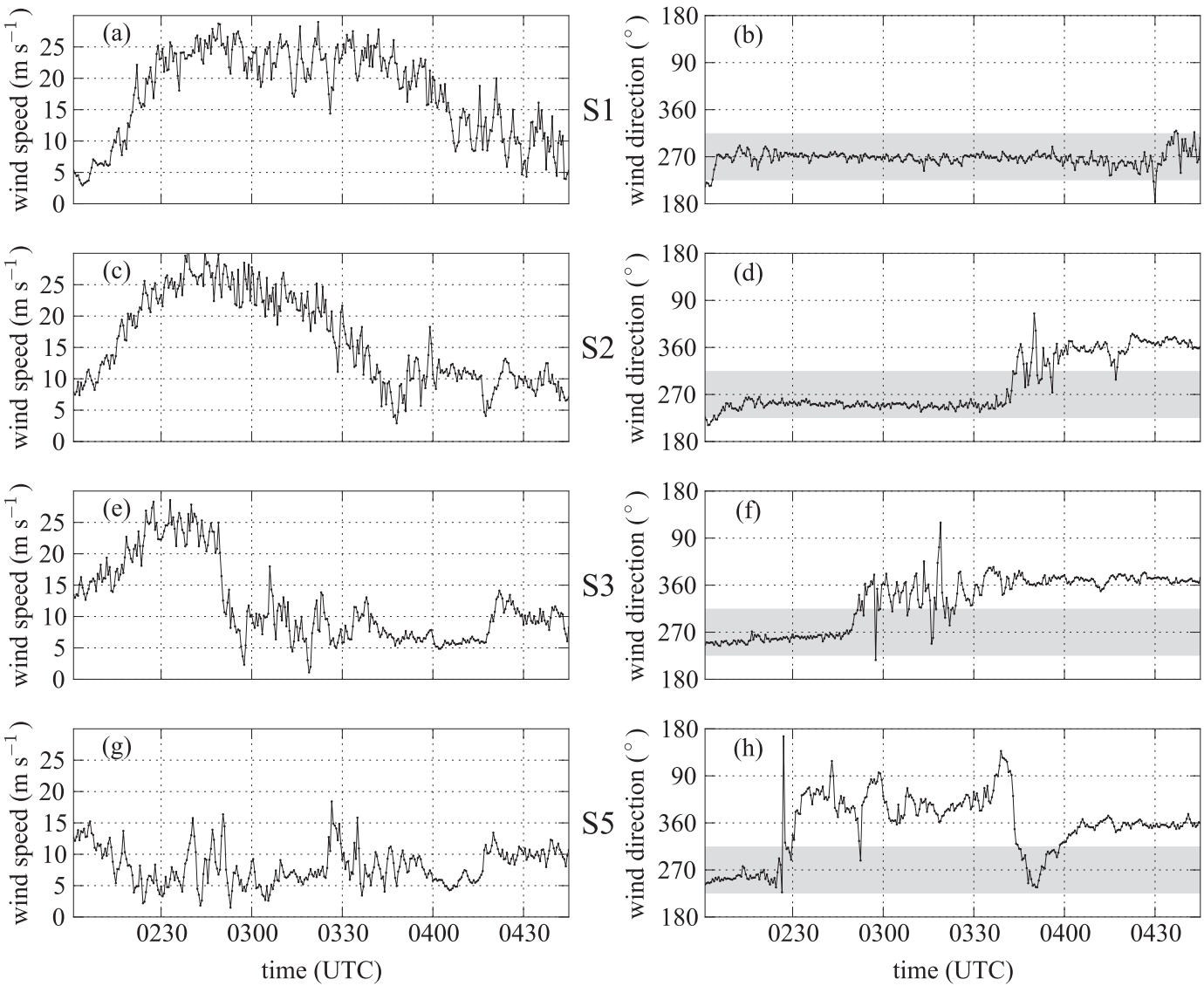

FIG. 10. Surface station measurements of (a),(c),(e),(g) wind speed and (b),(d),(f),(h) wind direction in the period from 0200 to 0445 UTC 26 Mar 2006. The stations 1, 2, 3, and 5 of the DRI surface network are shown in (a),(b); (c),(d); (e),(f); and (g),(h), respectively. The position of station 2, which has been added compared to Fig. 6 , is in the middle between stations 1 and 3 . Note also the different alignment of the $y$ axis in the right panel compared to Fig. 6.

present in this period of the downslope windstorm. Specifically, the coherent region of reversed flow can be seen eastward of the rising branch of the rotor in certain time intervals (Figs. 11b,c). The horizontal distance between the flow separation point and the maximum of the reversed flow is $\approx 5 \mathrm{~km}$. The reversed flow maximum was $\approx 4-5 \mathrm{~m} \mathrm{~s}^{-1}$ in magnitude and occurred a few hundred meters above the surface. The overall horizontal and vertical extent of this rotor is $\sim 6-8$ and $\sim 2-3 \mathrm{~km}$, respectively. In accordance with the westward propagation of reversed flow, we note an increase of its magnitude in time (cf. Figs. 11a,c), as the divergence zone approached the lidar site.

\section{Conclusions}

In this paper, we present high-resolution Doppler lidar observations of two different cases of transient downslope flows observed during the IOP6 of T-REX.
Although both events are characterized by favorable conditions for the formation of trapped lee waves and rotors (upstream wind profiles with a positive shear and a pronounced temperature inversion near the mountain crest level) they substantially differ in the observed wind field in the Owens Valley. The Doppler lidar observations allowed, for the first time, a comprehensive investigation of the internal structure of rotor flows underneath the mountain lee waves.

First, we reported about the transient downslope winds that were observed during the local morning hours of 25 March 2006. The observations were conducted during the breakup of the nocturnal inversion and before the passage of a cold front. At particular times of the selected period, the observations showed a rapid deceleration of the westerly downslope flow ending in a nearly vertical convergence line which resembles an internal hydraulic jump (Armi and Mayr 2011). The boundary layer flow 


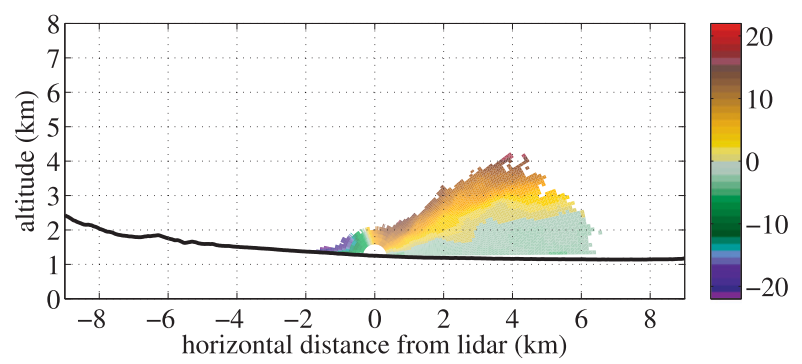

(a)

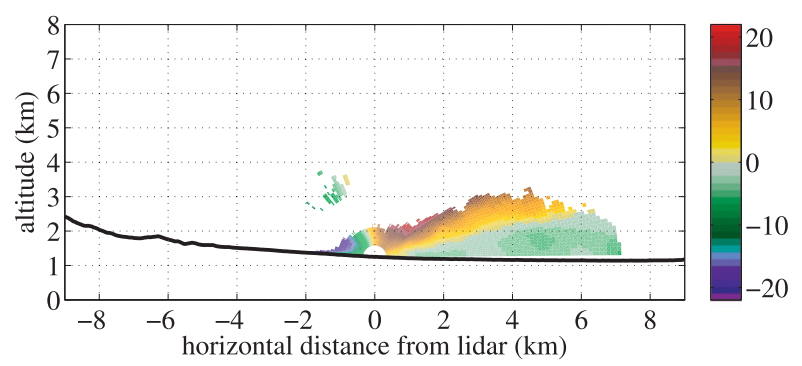

(b)

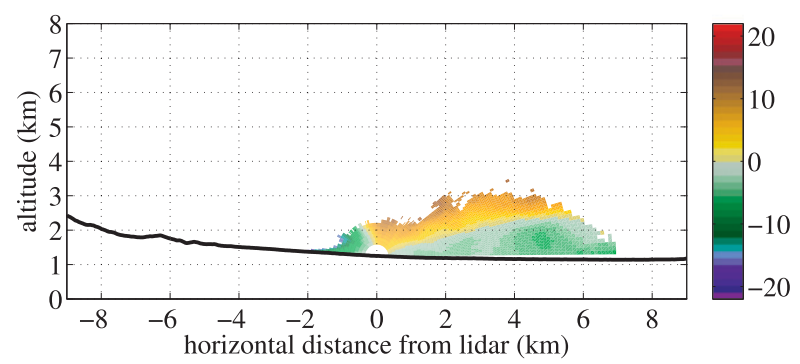

(c)

FIG. 11. Vertical slices of 10-min-averaged radial velocity $\left(\mathrm{m} \mathrm{s}^{-1}\right.$, shaded) during the nighttime observations. Averaging periods are (a) 0303-0313, (b) 0313-0323, and (c) 0318-0328 UTC 26 Mar 2006 (cf. the Hovmöller diagrams in Fig. 9). See Fig. 7 for further details.

downstream of the internal hydraulic jump was characterized by turbulence but no coherent rotor circulation was observed.

Considering the transient behavior of the first case, the continuous Doppler lidar observations allowed us to design Hovmöller diagrams to visualize the temporal evolution of the flow. These Hovmöller diagrams clearly document the intermittent character of the downslope winds as high-momentum air penetrated into the valley regularly in intervals of about $60 \mathrm{~min}$. At the leading edges of the downslope winds, the internal hydraulic jump propagated throughout the range of the lidar several times within a few hours. Thus, we concluded to interpret this case as a downslope windstorm with transient internal hydraulic jump.
The second case was observed after sunset on the same day and was associated with the interaction of the cold front with the mountain topography. A detailed analysis of the corresponding thermodynamical conditions of this event is still pending and here we reported about the Doppler lidar observations in the Owens Valley and the striking implications with respect to the low-level flow structure.

In contrast to the morning event, the downslope flow was much stronger and the Doppler lidar observations manifested horizontal winds in the boundary layer larger than $25 \mathrm{~m} \mathrm{~s}^{-1}$, which occasionally extended deep into the Owens Valley. At the leading edge of this downslope windstorm, a rapid flow deceleration associated with a concomitant flow separation from the surface was observed. Farther east to this internal hydraulic jumpa pronounced region of converging flow-distinct regions of reversed flow were observed by the Doppler lidar. In some sense, the correspondent 2D depiction of the observed flow field resembles the classical notion of a rotor. We also found a corresponding divergence zone in the Doppler lidar observations farther east, which could represent the downwelling branch of the rotor. In our observations, this low-level rotor flow was highly transient and intermittent and the recirculation zone of the downslope windstorm interacted with the northerly along-valley flow that was present after the passage of the cold front. Based on these characteristic properties, this case is interpreted as a downslope windstorm with transient rotor flow.

Throughout the six weeks of the T-REX Doppler lidar deployment in the Owens Valley, we observed several downslope windstorms with flow separation from the surface that were highly transient, intermittent, and exhibited a complex three-dimensional structure. Some observations comprise periods of a reversed flow component downstream of the separation point, as documented here for the second case. However, it appears that there is nearly always an interaction with a significant along-valley flow (thermally or pressure-gradient driven). Generally, the three-dimensional flow structure complicates diagnosis and interpretation of the rotor flow.

In response to comments on an earlier version of this paper, we have conducted 2D, high-resolution numerical simulations of the flow past the Sierra for the considered period using the same computational setup of the EULAG model (Eulerian/semi-Lagrangian fluid solver, Prusa et al. 2008) as presented in Doyle et al. (2011b). The aim was to compare the instantaneous flow field with time-averaged results. A comprehensive series of simulations was performed for different mountain profiles, initial times, and for varying spatial and 

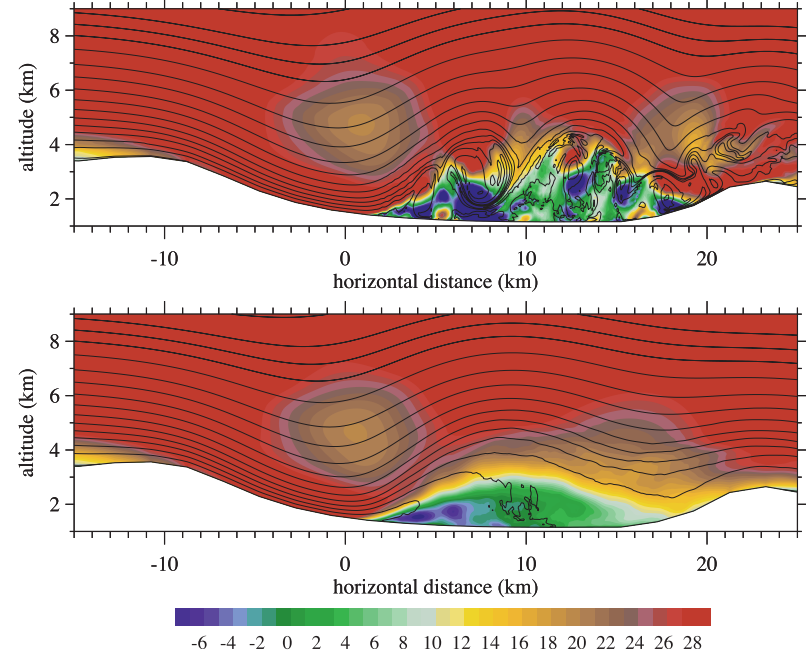

FIG. 12. Horizontal wind ( $\mathrm{m} \mathrm{s}^{-1}$, shaded) and potential temperature (black lines, $\Delta \theta=2 \mathrm{~K}$ ) along a west-east-aligned vertical section through Independence, CA. (top) Instantaneous values at $t=120$ min simulation time; (bottom) temporal average taken at each time step $\Delta t=0.25 \mathrm{~s}$ over the preceding $60 \mathrm{~min}$. The simulation was initialized by an upstream sounding taken from the ECMWF operational analysis at position $36.6^{\circ} \mathrm{N}, 120^{\circ} \mathrm{W}$ at $1800 \mathrm{UTC} 25 \mathrm{Mar}$ 2006. Horizontal and vertical grid spacings are $\Delta x=100 \mathrm{~m}$ and $\Delta z=20 \mathrm{~m}$, respectively.

temporal resolutions. All simulations show the same behavior when comparing the instantaneous and the time-averaged flow as in Fig. 12. While the instantaneous flow field is full of intermittent vortices interacting at different scales, the averaged results reveal a single rotor with a coherent near-surface reversed flow in the region underneath the quasi-stationary mountain lee waves. Likewise, in creating simple concepts from observations in nature, one tends to generalize and to assemble experiences from many different representations of the real flows disregarding secondary details. It is this difference that must be considered when one talks about the classical notion of a rotor. The numerical results demonstrate that the rotor as a concept may be a useful generalization, but the actual realization constitutes a fully turbulent flow of multiple scales.

Acknowledgments. The efforts of the National Center for Atmospheric Research (NCAR) Field Project Support (FPS) and the T-REX staff are greatly appreciated. The primary sponsor of T-REX is the U.S. National Science Foundation (NSF). The Deutsches Zentrum für Luft- und Raumfahrt (DLR) lidar observations were sponsored by funds from the Austrian Science Foundation (FWF) and internal funds of DLR. The authors are thankful to Georg Mayr from the University Innsbruck for support and useful discussions. We are also thankful to Kathrin Folger (Ludwig-MaximiliansUniversität München) for analysis of the surface station measurements. Furthermore, we gratefully acknowledge comments from two reviewers that helped to improve the presentation. We thank ECMWF for providing computing resources.

\section{REFERENCES}

Armi, L., and G. J. Mayr, 2011: The descending stratified flow and internal hydraulic jump in the lee of the Sierras. J. Appl. Meteor., 50, 1995-2011.

Birner, T., A. Dörnbrack, and U. Schumann, 2002: How sharp is the tropopause at midlatitudes? Geophys. Res. Lett., 29 (14), $1700-1703$

Cohn, S. A., V. Grubišić, and W. O. J. Brown, 2011: Wind profiler observations of mountain waves and rotors during T-REX. J. Appl. Meteor., 50, 826-843.

Darby, L. S., and G. S. Poulos, 2006: The evolution of lee-wave rotor activity in the lee of Pike's Peak under the influence of a cold frontal passage: Implications for aircraft safety. Mon. Wea. Rev., 134, 2857-2876.

De Wekker, S. F. J., and S. D. Mayor, 2009: Observations of atmospheric structure and dynamics in the Owens Valley of California with a ground-based, eye-safe, scanning aerosol lidar. J. Appl. Meteor. Climatol., 48, 1483-1499.

Dörnbrack, A., R. Heise, and J. Küttner, 2006: Wellen und Rotoren. Promet, 32, 18-24.

Doyle, J. D., and D. R. Durran, 2002: The dynamics of mountainwave-induced rotors. J. Atmos. Sci., 59, 186-201. and - 2007: Rotor and subrotor dynamics in the lee of three-dimensional terrain. J. Atmos. Sci., 64, 42024221.

V. Grubišić, W. O. J. Brown, S. F. J. de Wekker, A. Dörnbrack, Q. Jiang, S. D. Mayor, and M. Weissmann, 2009: Observations and numerical simulations of subrotor vortices during T-REX. J. Atmos. Sci., 66, 1229-1249.

Q. Jiang, R. B. Smith, and V. Grubišić, 2011a: Threedimensional characteristics of stratospheric mountain waves during T-REX. Mon. Wea. Rev., 139, 3-23.

—, and Coauthors, 2011b: An intercomparison of T-REX mountain-wave simulations and implications for mesoscale predictability. Mon. Wea. Rev., 139, 2811-2831.

Drechsel, S., M. Chong, G. J. Mayr, M. Weissmann, R. Calhoun, and A. Dörnbrack, 2009: Three-dimensional wind retrieval: Application of MUSCAT to dual-Doppler lidar. J. Atmos. Oceanic Technol., 26, 635-646.

Förchgott, J., 1949: Wave streaming in the lee of mountain ridges. Bull. Meteor. Czech., 3, 49.

Glickman, T., Ed., 2000: Glossary of Meteorology. 2nd ed. Amer. Meteor. Soc., 855 pp.

Grubišić, V., and J. P. Kuettner, 2003: Terrain-Induced Rotor Experiment (T-REX). Preprints, 10th AMS Conf. on Mesoscale Processes, Portland, OR, Amer. Meteor. Soc., 11.3.

— , and B. J. Billings, 2007: The intense lee-wave rotor event of Sierra Rotors IOP 8. J. Atmos. Sci., 64, 4178-4201.

— , and Coauthors, 2008: The Terrain-Induced Rotor Experiment. Bull. Amer. Meteor. Soc., 89, 1513-1533.

Hertenstein, R. F., and J. P. Kuettner, 2005: Rotor types associated with steep lee topography: Influence of the wind profile. Tellus, 57A, 117-135. 
Hill, M., R. Calhoun, H. J. S. Fernando, A. Wieser, A. Dörnbrack, M. Weissmann, G. Mayr, and R. Newsom, 2010: Coplanar Doppler lidar retrieval of rotors from T-REX. J. Atmos. Sci., 67, 713-729.

Holmboe, J., and H. Klieforth, 1957: Investigations of mountain lee waves and airflow over the Sierra Nevada. Final Rep., Contract AF19(604)-728, University of California AD 133606, Los Angeles, CA, 290 pp.

Jiang, Q., and J. D. Doyle, 2009: The impact of moisture on mountain waves during T-REX. Mon. Wea. Rev., 137, 3888-3906.

_ _ _ S. Wang, and R. B. Smith, 2007: On boundary layer separation in the lee of mesoscale topography. J. Atmos. Sci., 64, 401-420.

_- M. Liu, and J. D. Doyle, 2011: Influence of mesoscale dynamics and turbulence on fine dust transport in Owens Valley. J. Appl. Meteor., 50, 20-38.

Kuettner, J. P., 1938: Moazagoatl und Föhnwelle. Beitr. Phys. Freien Atmos., 25, 79-114.

, 1939: Zur Entstehung der Föhnwelle. Beitr. Phys. Freien Atmos., 25, 251-299.

Ludlam, F. H., and R. S. Scorer, 1957: Cloud Study: A Pictorial Guide. John Murray Ltd., 80 pp.

Mobbs, S. D., and Coauthors, 2005: Observations of downslope winds and rotors in the Falkland Islands. Quart. J. Roy. Meteor. Soc., 131, 329-351.
Neiman, P. J., R. M. Hardesty, M. A. Shapiro, and R. E. Cupp, 1988: Doppler lidar observations of a downslope windstorm. Mon. Wea. Rev., 116, 2265-2275.

Prusa, J. M., P. K. Smolarkiewicz, and A. A. Wyszogrodzki, 2008: EULAG, a computational model for multiscale flows. Comput. Fluids, 37, 1193-1207.

Ralph, F. M., P. J. Neiman, T. L. Keller, D. Levinson, and L. Fedor, 1997: Observations, simulations, and analysis of nonstationary trapped lee waves. J. Atmos. Sci., 54, 1308-1333.

Sheridan, P. F., and S. B. Vosper, 2006: A flow regime diagram for forecasting lee waves, rotors and downslope winds. Meteor. Appl., 13, 179-195.

— and - 2012: High-resolution simulations of lee waves and downslope winds over the Sierra Nevada during T-REX IOP 6. J. Appl. Meteor. Climatol., 51, 1333-1352.

Smith, R. B., B. K. Woods, J. Jensen, W. A. Cooper, J. D. Doyle, Q. Jiang, and V. Grubišić, 2008: Mountain waves entering the stratosphere. J. Atmos. Sci., 65, 2543-2562.

Vosper, S. B., 2004: Inversion effects on mountain lee waves. Quart. J. Roy. Meteor. Soc., 130, 1723-1748.

Weissmann, M., A. Dörnbrack, and J. D. Doyle, 2009: Vorticity from line-of-sight lidar velocity scans. J. Atmos. Oceanic Technol., 26, 2683-2690.

Whelan, R. F., 2000: Exploring the Monster. Mountain Lee Waves: The Aerial Elevator. Wind Canyon Books, 169 pp. 